\title{
Concepções de gênero entre homens e mulheres de baixa renda e escolaridade acerca da violência contra a mulher, São Paulo, Brasil
}

\author{
Gender conceptions related to violence against women among men \\ and women of low income and low educational level, Sao Paulo, Brazil
}

Márcia Thereza Couto ${ }^{1}$ Lilia Blima Schraiber 2 Ana Flávia Pires Lucas d'Oliveira ${ }^{2}$ Ligia Bittencourt Kiss ${ }^{2}$
${ }^{1}$ Departamento de Ciências da Saúde, Unifesp; Programa de PósGraduação em Medicina Preventiva, Faculdade de Medicina da USP.

2 Departamento de Medicina Preventiva, Faculdade de Medicina, USP. Av. Dr. Arnaldo, 455, sala 2239, Cerqueira César, 01246-903 São Paulo SP. liliabli@usp.br

\begin{abstract}
This article discusses how men and women oflow income and educational level, living in São Paulo City, think their affective and familiar relationships and the different violent contexts they live in. It consists of a qualitative study, based on focus groups and subsiding a more global study on violence against women and health. It has been conducted four groups (two with men and two with women, aging 25 to 35 years) broaching, free and instigated by popular sayings, conceptions on: the ideal man and woman, concretely experienced sexual affective and familiar relationships and on domestic violence. Thematic analysis was used. The results point in the direction of the division between physical attributes and moral conduct in the ideal woman referred by men, whereas the one referred by women defines a controlled autonomy. Men had difficulties in defining the ideal men, while, for women, this ideal is the family man. Violence is, in principle, always condonable. It is tolerable and instintictive for men, and fatality or destiny, because of masculine nature, for women, becoming a natural and trivial event in both of them day-to-day lives. The gender frame allows the comprehension of violence as a common occurrence, but in different senses for each of the genders
\end{abstract}

Key words Violence against women, Family, Masculine éthos, Feminine éthos, Gender
Resumo Otrabalho aborda como homens e mulheres de baixa renda e escolaridade, da cidade de São Paulo, Brasil, pensam suas relações afetivo-familiares e os diferentes contextos de violência que vivenciam. Trata-se de estudo qualitativo, utilizando grupos focais, com vistas a subsidiar estudo mais global acerca de violência contra a mulher e saúde. Foram realizados quatro grupos focais (dois com mulheres e dois com homens, na faixa etária de 25 a 35 anos), abordando as representações, livres e instigadas por ditos populares, de: homem e mulher ideais; as relações afetivo-sexuais e familiares; os concretamente vividos; e a violência doméstica. Usa-se a análise temática. Os resultados apontam para cisões entre atributos físicos e condutas morais na mulher ideal referida pelos homens, já aquela referida pelas mulheres define uma autonomia controlada. Os homens tiveram dificuldades em definir o homem ideal, já para as mulheres o ideal é o homem-família. Quanto à violência, é em princípio sempre condenável. É tolerável e instintiva para homens; e fatalidade ou destino, pela natureza masculina, para mulheres, tornando-se evento natural e trivial dos cotidianos de ambos. O referencial de gênero permite compreensão da violência como ocorrência comum, mas de sentidos diferentes entre gêneros.

Palavras-chave Violência contra a mulher, Família, Éthos masculino, Éthos feminino, Gênero 


\section{Introdução}

Circulando nos fóruns de debates na academia e/ou na prática dos movimentos reivindicatórios, sobretudo do movimento feminista, desde a década de 1980, diferentes sujeitos buscam entender os riscos diferenciados para homens e mulheres de agredirem e serem agredidos, assim como as possibilidades de acessar recursos, igualmente diferenciados, para enfrentar esses riscos. No âmbito deste debate está a violência contra a mulher, fortemente localizada no espaço doméstico e praticada por conhecidos, parentes e, principalmente, maridos e companheiros. Como apontam Schraiber e d'Oliveira ${ }^{1}$, a partir dos anos 90 , a problemática da violência contra a mulher passa a ser incorporada ao campo da saúde, sobretudo em razão do conhecimento crescente sobre a magnitude e agravos à saúde física e mental, produzidos pela experiência da violência psicológica, física e/ou sexual.

Aproximar-se das questões ligadas às relações cotidianas entre homens e mulheres e os conflitos que se originam nesse contexto, que, por vezes, culminam em situações de violência, além de contribuir para o debate teórico conceitual sobre o tema no campo da Saúde Coletiva, alimenta a discussão sobre as possibilidades e limites das respostas assistenciais da saúde à violência.

Violência familiar ou intrafamiliar, violência doméstica, violência nas relações amorosas e conjugais, violência contra a mulher, violência de gênero... muitas são as denominações usadas nos estudos e estas guardam como referências não apenas o país de origem - Brasil, Estados Unidos, países da Europa -, mas também os enfoques teórico-analíticos e políticos arrolados para a compreensão e ação diante da problemática. Embora não caiba discutir aqui tais diferenciações, muitas vezes sutis, é necessário deixar claro que a opção teórico-política que informa este trabalho vincula-se à perspectiva de gênero. Entre outros aspectos, tal recorte traz importantes contribuições para o enriquecimento da emergente área de estudos na interface entre Ciências Sociais e Saúde Coletiva, questionando a essencialização que toma a mulher como universalmente "vítima" da violência de homens e estes, da mesma forma, essencialmente agressivos. Essa perspectiva não reduz as raízes da violência às desigualdades de classe, ao revelar que ela se expressa de forma tocante em todos os segmentos sociais ${ }^{2,3}$.

A violência contra a mulher associa-se, sobretudo, ao domínio doméstico ou da casa, espaço social ligado à família, segurança, lealdade, companheiris- mo, solidariedade ${ }^{4}$. Relativamente a esse espaço social, há que se pensar como as transformações históricas imprimiram rearranjos nas relações entre os sujeitos da família e também nas relações afetivo-conjugais, para todas as camadas sociais.

O objetivo deste estudo é problematizar os limites das abordagens tradicionais sobre violência contra a mulher, na medida em que se busca apresentar alguns alcances da noção de gênero, não apenas para repensar as relações de poder e hierarquia nos domínios da casa e da família, mas a forma como as relações de poder e desigualdade nesses espaços fomentam conflitos e violências ${ }^{5}$.

\section{Metodologia}

Os dados que informam esta discussão são parte de uma pesquisa maior, de desenho qualitativo e quantitativo, que compôs um estudo de caráter multicêntrico sobre Saúde da Mulher e Violência Doméstica. No componente qualitativo, buscou compreender os significados atribuídos por homens e mulheres ao cotidiano das relações afetivo-familiares e às irrupções de situações de violência nessas relações. Esta pesquisa, coordenada pela Organização Mundial da Saúde (OMS): WHO Multicountry Study on Women's Health and Domestic Violence, com 10 países participantes, investigou, no Brasil, o município de São Paulo e 15 municípios da Zona da Mata de Pernambuco ${ }^{5}$.

$\mathrm{Na}$ dimensão qualitativa, além de entrevistas com informantes-chave de serviços e em profundidade com mulheres em situação de violência, foram realizados 16 grupos focais, dos quais 8 com moradores de São Paulo, sendo 4 deles com participantes de baixa renda e escolaridade. É deste último segmento que trataremos no presente artigo. Dois desses grupos foram realizados com homens e outros dois com mulheres. Os grupos contaram com 1 moderador(a) e 1 relator(a) independente, mantendo-se a identidade de gênero, isto é, grupos de homens moderados e relatados por homens; $\mathrm{e}$ de mulheres, por mulheres, seguindo recomendação internacional nos estudos de violência de gênero como princípio da coleta de dados $^{6}$. Houve uso de gravação como memória auxiliar da relatoria. A captação dos participantes foi feita por empresa consagrada de pesquisa de mercado em São Paulo, com larga experiência em grupos focais e por meio de convite a indivíduos de seus bancos de dados. O corte de renda (máximo de 5 salários mínimos), escolaridade (até a $8^{\mathrm{a}}$ série) e faixa etária ( 25 a 35 anos) foi por nós estabelecido previamente e entregue à empresa como critérios de seleção dos possíveis indivíduos convidados. 
O roteiro de questões foi constituído de três blocos temáticos. O primeiro abordava a percepção da mulher e do homem ideal; o segundo, as relações entre homens e mulheres; e o terceiro, a violência contra mulheres. Neste terceiro bloco usou-se a técnica de colagem realizada com material de um banco de imagens. Foram oferecidas 41 imagens de recortes de revistas variadas, que retratavam desde situações harmônicas entre o casal e a família, passando por possíveis fatores ou situações que levariam à violência, até imagens de violência explícita. A cada participante foi solicitado que montasse um painel retratando os principais problemas/conflitos enfrentados na relação entre homens e mulheres. Após o trabalho individual, o(a)s moderadore(a)s dos grupos pediam que cada um apresentasse seu painel, tendo por base algumas questões que eram apresentadas (Como a violência ocorre? Em que situações? Onde? Quais são suas causas? Por que ela ocorre? Em que situações ela pode ser aceitável? Quando não?). Todas as questões eram discutidas conjuntamente, à medida que cada participante apresentava seu painel, conformando uma discussão mais geral, dentro dos princípios desta técnica de investigação.

A análise do material foi realizada segundo a técnica de análise temática de conteúdo, a partir da leitura exaustiva do material transcrito das fitas, cotejado com os relatórios de cada sessão de grupo. A partir dessa leitura exaustiva, identificamos temas e categorias recorrentes, para estabelecermos as categorias analíticas que conduziram a análise comparativa, pautada no conceito de gênero ${ }^{7}$.

\section{Resultados}

\section{Os sujeitos participantes}

Os grupos foram realizados no ano $2000 \mathrm{e}$ tiveram duração média de 1 hora e 30 minutos. A amostra final dos grupos focais compreendeu 17 homens e 21 mulheres.

Os homens apresentaram idade média de 31 anos e trabalhavam em ocupações de baixa remuneração (como segurança, vigilante, corretor de seguros, auxiliar da promotoria, vendedor, auxiliar administrativo, motociclista, auxiliar de mecânico, contínuo, ajudante geral, supervisor de manutenção, auxiliar de almoxarifado, ourives e fiscal de roteiro). A média de renda familiar foi de $\mathrm{R} \$ 546,00$ (3,61 salários mínimos em 2000). Em relação à escolaridade, 14 tinham o curso fundamental incompleto (da $5^{\mathrm{a}}$ a $7^{\mathrm{a}}$ série) e 3 não chegaram a iniciar a $5^{\text {a }}$ série. No que diz respeito à situação conjugal, 12 eram casados, 3, separados e 2, solteiros. Quatro deles não tinham filhos, 7 tinham dois filhos e os 6 restantes, um. O tempo médio de relacionamento dos casados foi de 5 anos e meio.

Quanto às mulheres, a idade média foi de 31 anos. Doze trabalhavam em ocupações de baixa remuneração, enquanto 6 eram donas de casa e 3, desempregadas. A média de renda familiar foi de R\$512,00 (3,39 salários mínimos em 2000). Em relação à escolaridade, 3 mulheres completaram o ensino fundamental, 16 haviam cursado ensino fundamental incompleto e 2 sem ensino formal. No que diz respeito à situação conjugal, 15 delas eram casadas, 5 separadas e 1 viúva. Apenas 3 mulheres não tinham filhos, sendo que 14 tinham até 3 filhos e 4 tinham 4 filhos. A média de tempo de relacionamento das casadas foi de 6 anos.

\section{O ideal de mulher e homem nas falas dos homens}

Entre os homens, a mulher ideal foi construída tendo como base uma dupla referência: a primeira, e principal, foi o comportamento das parceiras no interior do relacionamento; a segunda foi referida às imagens femininas que circulam na mídia, constituindo o padrão de beleza nacional. Quanto ao primeiro aspecto (atributos da parceira), a representação da mulher ideal remete, para boa parte dos homens, à inteligência, à maturidade, à responsabilidade, ao resguardo e à dedicação, atributos considerados e valorizados como pilares do relacionamento. A segunda referência teve como eixo os critérios de beleza física e sensualidade que se reúnem numa mulher distante (atrizes, dançarinas e modelos em destaque na mídia) ou, muitas vezes, imaginária: "[...] um metro e sessenta, 59 quilos, bunda bem feitinha...." E um outro complementa: "Mulher sem bunda, para mim, não tem graça".

Alguns participantes responderam que a mulher ideal deve ser "inteligente, dinâmica, arrojada", sendo desprezada aquela que não trabalha e, portanto, depende do homem. Nesse aspecto, é pertinente a observação de Giffin ${ }^{8}$. No trabalho com grupos focais masculinos de camadas populares, segundo elas, o que se observa é a transformação do modelo ao longo das três últimas décadas. Se nos anos 70 os homens consideravam as atividades extradomésticas das esposas algo tolerável apenas circunstancialmente, nos anos 80 e 90, os homens passam a considerar o trabalho algo que é bom para a própria mulher, sendo que alguns enfatizam que 
a mulher deve ter uma ocupação fora de casa e contribuir para o sustento da família. No entanto, percebemos que há contradições na exposição das idéias associadas à emancipação feminina, já que muitos homens apontaram claramente que o excesso de liberdade que o homem dá à mulher pode trazer o perigo do desrespeito e da infidelidade feminina. Além disso, a própria idéia da liberdade feminina difere bastante da visão que esses homens possuem da própria liberdade. Há ambigüidades na definição masculina dos espaços de liberdade e autonomia da mulher, que não devem esbarrar nas fronteiras do poder masculino estabelecido. Se, para os homens, o exercício da sua liberdade depende da não interferência e controle femininos no seu espaço/tempo de lazer, a liberdade que pensam para as mulheres restringe-se à circulação no espaço público para fins de trabalho e à autonomia decisória nas questões domésticas.

Sexo e controle da sexualidade feminina foram temas também centrais nas discussões dos grupos masculinos em torno da mulher ideal. Esses aspectos evidenciam o conflito entre o ideal, que prioriza a emancipação feminina, e aquele que vê, na passividade, uma característica da mulher ideal. A partir do momento em que a satisfação sexual entra em pauta, a referida tensão entre os dois ideais de mulher torna a se manifestar. As características físicas substituem o caráter como referencial de construção da imagem ideal feminina. Um deles resume bem a percepção masculina: Os homens dizem: mulher ideal é aquela arrojada, independente, compreensiva... mas no fundo, no fundo, a ideal, e a que todo mundo quer, é aquela que é objeto sexual dele. Ninguém tá falando, maséverdade, todo mundo pensa isso.

A construção da imagem do homem ideal toma como base uma leitura de "segunda mão" do ponto de vista do "outro", a mulher. Na descrição dos atributos ideais dos homens, a referência adotada é o que pensam ser a expectativa das mulheres e não a deles próprios. Os homens entendem que o homem ideal para as mulheres é aquele que "ajuda" em casa, é prestativo, dedica-se à família, é gentil (mas não "viado/delicado") e companheiro. Esse ideal é construído em oposição àquele do homem agressivo, que bebe, usa drogas e bate na mulher.

Esse ideal masculino corresponde, grosso modo, ao discurso feminino sobre o ideal de homem. Em ambas as falas, a reciprocidade faz parte das expectativas femininas em relação aos homens, mas mesmo insistindo nesta reciprocidade, há um esforço de manutenção da dissimetria entre os gêneros. $\mathrm{O}$ homem deve contribuir, mas sem assumir as tare- fas tidas tradicionalmente como responsabilidades femininas, correndo o risco de ver assim a sua masculinidade/virilidade questionada. A partir da discussão entre os homens a respeito do homem ideal, a violência entrou espontaneamente no debate através dos atributos do tipo oposto ao ideal. Alguns casos foram relatados.

Quanto ao exercício de construção/discussão sobre homem e mulher ideais para os participantes, é possível argumentar que, se em relação à mulher ideal foi possivel traçar um perfil mais unificado (embora polarizado entre a mulher dos atributos físicos e a mulher dos atributos morais), no que diz respeito ao homem houve dificuldade em sintetizar características que definissem o ideal de homem: ou porque se mostram resistentes a qualquer proposta de elaboração de um padrão ideal de homem, como na frase: "o homem não vale nada"; ou porque apontam para a dificuldade de eleger características mais ou menos recorrentes, pois percebem que há tantos tipos ideais de homens, quanto as fantasias e os referenciais das mulheres. Um deles comenta: É difícil dizer um único homem ideal para uma mulher. Porque cada uma tem um gosto, umas já gostam de um cara carinhoso, outras de um mais machão... outras gostam de malandro.

O que fica claro é que a maior dificuldade na representação do homem ideal está no fato de que, como homens reais, eles acham difícil encontrar atributos próprios e os mesclar com valores que consideram pertinentes para construir a imagem do homem ideal. Por isso, firmam-se na construção do homem ideal a partir das supostas referências femininas sobre os homens em geral, e, por que não, sobre eles em especial.

\section{O ideal de mulher e homem na fala das mulheres}

De saída, é interessante notar que, ao contrário do que pudemos verificar no discurso masculino, em nenhum momento os atributos físicos foram elencados na elaboração da imagem ideal por parte das mulheres, embora as moderadoras tenham pontuado que na construção do homem ideal, as mulheres poderiam falar de todos os aspectos: físicos, comportamentais, de temperamento, atributos, habilidades, etc. Na construção do tipo ideal de homem, as mulheres explicitaram suas demandas sobre atitudes e comportamentos masculinos em relação a si próprias e à família. As mulheres também preferiram discutir sobre a constatação de que a perfeição é inatingível tanto em homens quanto em mulheres, mas alguns traços foram selecionados na elaboração da imagem que mais 
se aproximaria do tipo ideal de homem. A imagem construída rejeita a figura do típico patriarca que reuniria em si o poder de mando dentro do ambiente doméstico. Uma relação mais igualitária, na qual o companheirismo, a amizade e a dedicação fizessem parte do comportamento masculino em relação à cônjuge e aos filhos, foi, para essas mulheres, a base a partir da qual elas elaboraram o ideal de homem. Nesse sentido, o fato de compartilhar problemas e manter uma cumplicidade cotidiana seriam atributos essenciais neste "novo" homem. Dessa forma, o homem que se preocupa em participar da execução das tarefas domésticas e com o cuidado dos filhos foi valorizado em detrimento daquele que exerce sobre a esposa alguma forma de autoritarismo, exigindo dela obediência incondicional. Apesar disso, conforme mencionado anteriormente, há um esforço em conservar os lugares tradicionais das atribuições de gênero, que conferem à mulher maior responsabilidade na execução dos serviços domésticos. O sentimento de segurança do homem em relação à mulher e a certeza da submissão feminina dariam margem à dominação exercida por ele, o que poderia levar às conseqüências mais graves, chegando, inclusive, à agressão física.

Homem é muito mandão, ele acha que a mulher tem que obedecer, ir na linha... Mas não é assim.

A mulher fica ali, sempre obedecendo o marido. Ai ele pensa: "ah, eu domino ela", aí já quer bater, falar desaforo. Porque quando o marido fala uma coisa que ela não concorda... Aí ela tem que dizer: "não concordo". Deu primeiro tapa, e ela não fez nada, aí ele acostuma. Principalmente quando ele bebe.

No que toca à representação da mulher ideal, a primeira característica atribuída foi a independência em relação ao homem, no sentido de um projeto próprio. Dessa forma, a imagem da mulher ideal, na opinião das participantes, corresponderia àquela da mulher emancipada e independente, que trabalha fora, estuda e ainda é capaz de se preocupar com o marido e os filhos. Investe em sua vida profissional, ao mesmo tempo em que se dedica à vida familiar. Essa mulher deve ainda ter opinião própria. Apesar de valorizar essas características na mulher, houve a percepção de que esse conjunto de obrigações a sobrecarregaria. A falta de envolvimento masculino nessa dimensão da vida doméstica foi atribuída, entre outros fatores, à educação dada pelas mães aos meninos, que acabaria por deixá-los na confortável posição de quem recebe muito, fazendo pouco em troca. A reciprocidade, dessa forma, não faria parte do comportamento masculino em geral e, por este motivo, o trabalho da mulher em casa seria encarado como sendo fácil e de pouco valor.
A mulher se preocupa com a casa, com o lar, com o marido, com os filhos. Parece que nós nos preocupamos mais. Eles têm a responsabilidade de trabalhar, entre aspas, porque às vezes nem isso têm: "eu tô trabalhando, eu tô pagando, você faz o resto". Só que a mulher quando trabalha fora... ela chega em casa, tem que fazer um monte de coisa.

$\mathrm{O}$ excesso de independência, no entanto, é visto como um obstáculo à relação, pois produziria um sentimento competitivo no parceiro relacionado ao questionamento de seu papel de provedor e formador de opinião no espaço doméstico. Outra situação, potencialmente geradora de conflitos, que também produziria desentendimentos, seria o contexto oposto, em que a mulher somente ocupa-se do lar, não havendo reconhecimento pelo parceiro dos esforços que despende na execução das tarefas domésticas. Neste último contexto, o trajeto para a afirmação da autoridade masculina na casa apresentaria menos barreiras, visto a permanência de vínculos mais tradicionais de poder que implicam a valorização diferencial dos sexos.

Mas quanto mais a mulher é independente, o diálogo vai ficando difícil, porque ele vai sempre achar que você está querendo passar na frente dele, porque os dois trabalham, sustentam a casa, então quando você dá uma opinião...

[...] se ela só fica em casa, aí ele vai chamar ela de vagabunda, que não faz nada. Então, ela tem que ter o serviço dela.

Relações entre homens e mulheres:
éthos masculino e feminino entre
pessoas de baixa renda e escolaridade

Os aspectos que fomentam situações de violência podem ser analisados segundo uma lógica circular em que o desemprego - ou a impossibilidade de corresponder às suas expectativas e às expectativas dos outros (sobretudo da mulher e familiares) quanto ao sustento da família - representa um ponto de partida. O trabalho emerge, então, como condição que confere ao homem não apenas o sustento, mas a respeitabilidade diante da mulher, dos filhos e de outros homens. O dinheiro recebido por este trabalho é visto como fundamental na manutenção do casamento, sendo percebido como uma das principais demandas da mulher em relação ao seu parceiro. E, quando este falta, uma forte carga negativa (pessimismo, baixa auto-estima, insegurança...) é sentida por esses homens. Mesmo que eles não mencionem de forma explícita e direta toda a fragilidade por que passa um homem pobre/trabalhador nessas situações (talvez porque estão na presença de pares e o elogio de si 
é algo mais valorizado), os exemplos relatados, alguns pessoais, mas na maior parte sobre conhecidos e parentes, nos leva ao reconhecimento da importância do trabalho para esses homens. Um deles falou: "quando as dívidas entram pela porta, o amor sai pela janela".

É nesse momento de fragilidade do homem, que resulta em dificuldade de se reconhecer como figura central de autoridade perante a sua família, que o ideal de mulher companheira, atenciosa e que saiba compreender as inseguranças do marido voltam à tona. Alguns homens comentaram que, "pior do que perder o emprego ou estar desempregado é a cobrança feminina". Alguns dizem que quando não se estabelece uma relação de companheirismo entre o casal, tais cobranças podem redundar em situações de agressão verbal e, em casos mais extremos, agressão física. Um participante comenta:

Eu falo da minha situação: eu tô desempregado há dois anos e agora minha mulher não cobra mais... porque sentamos e conversamos sério. Mas no começo ela cobrava muito, e aí gerava muito conflito em casa.

Ao longo da discussão que se forma em torno das situações concretas de violência, observamos que a "cobrança" - algo natural da mulher - estende-se para outras esferas da vida conjugal, sendo a do ciúme uma das referidas. Volta à tona, mais uma vez, o ideal acima mencionado de mulher que é segura, dá liberdade e "não enche o cara". A mulher ciumenta, e real, é retratada como a má companheira, aquela que não procura viver em paz e harmonia, aquela que se mostra insegura e, como conseqüência, pode até gerar insegurança no homem. Voltam sempre, em todos os grupos, as referências da mulher ideal.

Essa imagem de mulher não se reproduz no discurso das mulheres. Ao contrário. As mulheres apontam a falta de diálogo na relação como responsável pela desunião do casal e por inúmeros episódios de desentendimento e brigas. Porque os homens são raramente companheiros (no sentido de dividir suas preocupações com a esposa e participar dos assuntos da casa), as mulheres se colocam no papel de cobrar o diálogo e a presença do homem na casa. A conversa freqüente entre marido e mulher seria um caminho para a paz e harmonia no ambiente doméstico. Embora reconheçam que a falta de diálogo não é de responsabilidade exclusiva do homem - sendo a impaciência da mulher para escuta um fator de entrave para a comunicação do casal -, são as mulheres que se colocam como tendo que "chamar o cara para casa, para a família e a mulher". Assim, ela reconhece que deve assumir responsabilidades no sentido de uma maior união da família.

Ainda para as mulheres, um dos sérios motivos de discussão seria a ausência masculina tanto na divisão das responsabilidades com a casa, como no reconhecimento da mulher como aquela que se esforça para manter a casa e a família "em ordem". Mesmo havendo um consenso entre as mulheres em torno da idéia de que o homem deveria ajudar mais nos serviços da casa e de que as expectativas do marido nesse sentido seriam muito altas, alguns chegando a considerar a mulher uma empregada, o homem que assume a responsabilidade por todas as tarefas nesse âmbito estaria assumindo o papel da mulher, o que não deveria ocorrer. A colaboração, e não necessariamente uma divisão igualitária dos serviços domésticos, é esperada dos homens. Está presente nestas considerações a referência aos papéis tradicionais de gênero, que parecem acarretar uma definição da situação em que é naturalizada a atuação de cada um na vida pública e privada. Enquanto se posicionam entre o questionamento das atribuições domésticas de modo desigual e o respeito à ordem que impõe a casa como de domínio e responsabilidade da mulher, elas iniciam um outro questionamento: o reconhecimento da reprodução desses papéis na própria educação diferenciada que algumas mulheres dão a seus filhos de acordo com o gênero destes.

$O$ sonho que a mulher tem... ter a família maravilhosa, a gravidez tranqüila... mas quando vê é tudo diferente: o homem faz dela Amélia, ela não fala nada; é briga, aí bate na frente das crianças e ela fica traumatizada... eu escolhi ser bem radical, mas é isso que acontece. Porque homem acha que trabalha, bota comida dentro de casa e acha que já fez tudo. Mas tratar a mulher bem, fazer carinho, levar para passear... aí eles acham que não têm obrigação. Porque não é só pôr comida dentro de casa.

Homem tem que colaborar, mas não é para assumir o papel da mulher.

Eu não concordo. Acho que a culpa é dos pais que dizem que filho homem não deve fazer nada, é só ser macho e tal. Eu não concordo. Acho que não é vergonha nenhuma para um homem lavar uma louça.

Um outro aspecto que une os homens em relação às causas da violência diz respeito ao dinheiro. Como já assinalado, para os homens das camadas mais populares, a falta de trabalho compatível com suas habilidades técnicas pouco especializada é um fator impeditivo para ganhos que possam satisfazer as necessidades de sua mulher e filhos. As cobranças das mulheres são, portanto, relacionadas ao desemprego ou à baixa remuneração, o que as obriga a sair em busca de rendimentos que complementem a renda familiar. 
O dinheiro aparece como pivô de conflitos, porque é colocado como responsabilidade masculina. Como precisam cumprir com o papel de provedor familiar, a falta de dinheiro pode gerar problemas em várias direções: não conseguir satisfazer os desejos de sua família, como comprar presentes para os filhos. A idéia da mulher gananciosa tanto a esposa quanto uma namorada - também traz certa insegurança, já que só saberão que ela de fato o é quando o dinheiro acabar, terminando o namoro ou o casamento. Ou ainda, a frustração por não estar cumprindo com o que acreditam ser seu papel: prover a casa.

\section{As expressões da violência e sua aceitabilidade: as percepções dos homens e mulheres}

Chamou atenção o fato de, à primeira vista, a violência ser considerada não justificável tanto para homens quanto para mulheres. Mas, a continuidade das discussões levantou a questão: se ela não é justificável, seria tolerável, em algumas situações? Enquanto as mulheres permaneceram na referência à violência como injustificável e intolerável, os homens consideraram a violência até certo ponto tolerável, já que instintiva e, portanto, incontrolável. Em alguns casos é tolerável ou compreensível o recurso à violência, disseram os homens, porque, afinal de contas, ela é o resultado da exacerbação de impulsos que são naturais aos homens.

A violência não acontece só entre homens, mas em todo o mundo animal. Você vê: o macaco bate na macaca. Existe o instinto do homem, dele bater.

Há que se destacar, porém, que entre as mulheres apareceram duas situações pensadas como aceitáveis: 1) a violência como revide, servindo como "lição" ao agressor e, assim, evitando ocorrência de novos episódios; 2) a violência contra as "mulheres que gostam de apanhar", reconhecendo que há esta situação, embora sem ter ficado muito claro se correspondia a um reforço ao senso comum masculino ou de possíveis situações particulares no exercício das relações afetivo-sexuais.

Do ponto de vista dos homens, os principais fatores causadores de situações violentas entre homens e mulheres foram: desemprego ou dificuldade financeira do homem; abuso de bebida alcoólica; ciúme, desconfiança e traição; cobrança e falta de compreensão da mulher. Já para as mulheres, a violência aparece principalmente como resultado do abuso de bebida ou uso de droga pelos homens, assim como pela má influência de amigos que afastam os homens da casa e das mulheres, trocando a re- lação com a mulher pelas farras, os bares e outras mulheres. Além disso, a falta de diálogo, a impaciência da mulher para a escuta, o fato de a mulher ser "complicada", o ciúme masculino excessivo e a dificuldade da mulher em reagir são apontados como possíveis causas de violência. Mas vejamos as implicações dos fatores relacionados à violência para os homens e as mulheres...

Com relação aos homens, é possível argumentar que os quatro grupos de fatores implicados nas situações de violência relacionam-se com os principais elementos estruturadores da condição de homem, especialmente quando se trata do meio popular. Quando questionados ou implicados num contexto real de impossibilidade de concretização, esses fatores provocam tensões nas relações entre homens e mulheres; que, não raro, são resolvidos por meio do recurso à violência.

Assim, com base na literatura socioantropológica sobre a constituição das masculinidades nos setores populares urbanos, vemos que determinados comportamentos masculinos são amplamente reconhecidos como atributos naturais do ser homem. Este é, por natureza, considerado sexualmente insaciável e, portanto, porque sente necessidade, pode ter relações extraconjugais. É também recorrente a associação entre ser homem e ser o provedor, moral e material, da família ${ }^{9-12}$. Quanto à referência à moral, esta é tida como valor e remete, sobremaneira, à questão da honra. Como bem definiu Pitt-Rivers ${ }^{13}$, quando associada à pobreza, a honra constitui-se em virtude moral, não estando associada simplesmente à posição social. Sendo a honra nas classes populares um dos principais pilares sobre os quais os homens constroem e vivenciam as relações com os "outros" (mulheres, homens mais pobres, homens mais ricos, crianças/adolescentes), não é de se estranhar que, na relação homem-mulher, a honra se constitua como elemento que está sempre à prova. Portanto, o medo da infidelidade feminina, que está associado à vinculação entre masculinidade e virilidade, está sempre presente.

Há ainda que considerar que o ciúme entre os homens esteve relacionado ao tema da traição, e este constituiu um dos mais importantes pontos de convergência acerca da tolerância da violência contra a mulher. Todos reconheceram que, de todas as situações de desentendimentos que possam ocorrer entre um homem e uma mulher, a que escapa do controle, sempre, é a da traição. Esta seqüência representa bem o argumento do conjunto dos participantes.

Moderador: [...] vocês imaginam outra situação em que pode acontecer violência? 
Participante 1: Traição.

Participante 2: [...] por mais compreensivo, por mais liberal que você possa ser... mas se você pega sua esposa, sua namorada, com outro [...] é difícil o cara se controlar

Participante 3: É natural.

Participante 4: Não que seja uma coisa justificável, mas é uma coisa do próprio instinto, a vontade é de bater, acabar com ela e com ele.

Observa-se, portanto, uma associação direta entre virilidade, honra, controle de si e masculinidade e violência. $\mathrm{O}$ conjunto desses traços parece compor um quadro que dá sustentação ao argumento, já enfatizado na literatura sobre gênero e violência, de que a violência conjugalafetiva emerge ante a impossibilidade de reproduzir um padrão de relacionamento entre os gêneros centrado na diferença (expressa em desigualdade).

Por fim, um outro aspecto que vale referendar quanto ao modelo de masculinidade nesse grupo social é o controle sobre a própria von$\operatorname{tade}^{12}$. O homem não deve jamais se submeter à vontade do "outro", especialmente quando este é tido como igual ou inferior na hierarquia social que estabelece espaços diferenciados de atuação para os sujeitos (mulheres e crianças, de forma geral, e "outros" homens que detêm menos prestígio: bêbados, miseráveis, vagabundos, homossexuais, entre outros).

\section{Discussão}

Gênero, família e algumas questões sobre conflitos, violência e saúde

Neste espaço, trata-se de discutir sobre os modelos de masculinidade e feminilidade introjetados pelos homens e mulheres como parte das representações deles acerca de relações afetivo-conjugais, sexuais e familiares, assim como as múltiplas realidades nas quais vivem. Na parte final deste ensaio, e de forma breve, pretendemos levantar algumas questões da forma como o imaginário de gênero e família repercute no desempenho social dos indivíduos. Isto como um recurso que ajuda a entender as tensões produzidas na impossibilidade, mais ou menos "dramática", de as pessoas atualizarem estes modelos de gênero e família, que podem dar forma a situações ou contextos de violência. Para tanto, tomamos o recorte das famílias de camadas populares por duas razões: primeiro, pela maior familiaridade com a temática da família nesses grupos sociais e, segundo, por reconhecer que são os membros dessas famílias (homens, mas especialmente mulheres e crianças) os principais interlocutores no diálogo entre os profissionais de saúde em serviços públicos de atenção primária e a população.

Segundo d'Oliveira ${ }^{14}$, a discussão sobre as possibilidades de estabelecer limites claros e definições precisas do que é violência, em geral, e do que é violência de gênero, em particular, tem mobilizado diferentes sujeitos, na academia e/ou na prática dos movimentos sociais. Embora não seja este o espaço apropriado para tratar em detalhe tais questões, é necessário assinalar a "orientação" seguida. E esta se apóia em d'Oliveira ${ }^{14}$, que entende que não é por considerar as diferenças de gênero postas na sociedade como desigualdades entre homens e mulheres que se deve tratar as mulheres como "objeto" da violência praticada por homens. Ao contrário. Mesmo sem negar as desigualdades e a posição desprivilegiada da mulher na sociedade, a autora reconhece que a mulher é "sujeito em situação", capaz de pensamentos e ações eticamente orientados.

Por outro lado, cabe reforçar que as relações de gênero comportam o mesmo substrato de todas as relações sociais: o poder. Assim, se entendemos o poder como fluido, disperso e não necessariamente exercido apenas por um, mas por ambos na relação - guardadas as singularidades e estratégias utilizadas no exercício do poder -, reconhecemos que a existência de conflitos e tensões permeia as relações sociais e, portanto, as relações de gênero; mas, não necessariamente, se desdobram em violência.

É importante ressaltar, também, que o recorte aqui proposto trabalha a especificidade cultural e simbólica das populações de pobres urbanos, como um todo, e de suas famílias, em especial. Tomamos como referência os trabalhos de Duarte ${ }^{15}$, para quem existem duas grandes matrizes culturais presentes nas sociedades contemporâneas. De um lado, a matriz dominante que teria como referente o individualismo; $\mathrm{e}$ a(s) outra(s), dominada(s), que possui(em) uma lógica mais holista. À maneira do autor, não reforçamos uma possível argumentação que sugere que os pobres urbanos possuem uma cultura específica e de todo separada do modelo dominante. Ao contrário, trabalhamos com a noção de que ela mantém uma relação bastante peculiar de leitura de mundo em que há uma interface direta e constante com os pressupostos centrais da modernidade. Assim, afirmar a positividade dos pobres urbanos significa não submetêlos ao olhar da falta, mas tomá-los como portadores de um sentido que, dado seu traço próprio, destoa das marcas do universo da modernidade, aqui especialmente pensada como aquela que dá 
suporte aos referentes da classe média. Em outras palavras, ao reconhecer o potencial desigual que as classes têm para difundir e legitimar sua visão de mundo, compreendemos que a relação entre elas se dá num intricado jogo de forças em que mesmo os mais despossuídos operam na afirmação e recriação de suas diferenças. Chamamos atenção, portanto, para a necessidade de evitar considerar os "pobres urbanos" uma categoria homogênea. Entendemos que um dos grandes desafios das ciências sociais foi o de quebrar ou desconstruir a noção "monolítica" de pobre e pensar a pluralidade e diversidade interna à categoria, em termos de gênero, classe, raça, etnia, idade, religião, etc.

Usando este referencial para "explorar" o universo simbólico das famílias nas camadas populares, um dado chama bastante atenção: a preeminência simbólica da família nos grupos populares. O todo relacional representado na família exprime-se através de uma divisão de trabalho entre os gêneros que é, ao mesmo tempo, moral e familiar. Nesse contexto, os atributos de gênero são tomados a partir de uma complementaridade hierárquica. Ao masculino está destinado uma maior exterioridade e a associação com o que é de domínio público, dimensão consolidada na esfera do trabalho. De forma complementar a este, emerge o privado, espaço associado à interioridade e ao domínio do natural, portanto espaço feminino. Ser homem significa, em termos ideais, exercer com firmeza o papel de provedor material e moral, o que garante o respeito por parte do grupo e perante o universo social que o rodeia. À mulher, em contrapartida, está associado o desempenho de tarefas como cuidar da casa, do marido e dos filhos.

Quando esse modelo de família e de relações entre os gêneros "colide" com uma realidade social que impulsiona os sujeitos a atuarem em outras esferas (a rua, para as mulheres que precisam sair à busca de trabalho para ajudar, ou mesmo prover todo o sustento da família; e a casa, para os homens que, desempregados, se vêem impossibilitados de cumprir o papel de provedor econômico, mas também moral), tensões e conflitos se acirram. Isso porque a complementaridade hierárquica no jogo das contradádivas sociais foi quebrada ou está sendo problematizada. Outros exemplos acerca dos distanciamentos entre modelos e práticas são assinalados por Suárez et al. ${ }^{16}$, especialmente no que toca às relações afetivo/conjugais. Segundo essas autoras, a quebra nas regras de reciprocidade permeia os discursos de "agressores" e "vítimas" sobre a violência doméstica. Ciúme, traição e vingança, recusa em desempenhar o "papel correto" de esposa/companheira e namorada (como ser recatada, servir sexualmente o homem, aceitar traição, etc.) fazem parte dos discursos de muitas mulheres que sofreram violência, mas também de homens, sobre as causas alegadas das agressões às suas mulheres.

Claro está que esta quebra dos papéis tradicionais representa a configuração crítica contemporânea, que convive com a condição convencional em que já se encontra um número elevado de parcerias nas quais, a despeito de os papéis tradicionais serem mantidos, a violência também ocorre. O que é provável é que essas duas modalidades de relacionamento - o relacionamento tradicional e aquele "em crise" de papéis - expressem situações, em termos de gravidade, freqüência ou mesmo fatores desencadeantes e/ou associados diferentes entre si, igualmente repercutindo nas formas de enfrentamento da violência, o que merece estudos mais aprofundados.

Levantar questões sobre a imbricada relação entre modelos e práticas vivenciados por homens e mulheres, mas também pais e filhos, parentes, enfim..., ou mesmo estudando-se os arranjos familiares tradicionais, tomando como aporte a perspectiva de gênero, pode nos ajudar a refletir, mais criticamente, sobre tensões, conflitos e contextos de violência com os quais nos deparamos no dia-a-dia. Essa reflexão é também crucial na produção da assistência em saúde, especialmente em casos de violência doméstica, em que o sentido da intervenção deve ser negociado de acordo com as demandas e necessidades que os sujeitos apresentam e que são formuladas a partir do contexto sociocultural e familiar específico em que os sujeitos vivenciam seus problemas.

Ademais, na saúde, resta, ainda, o desafio de incluir questões socioculturais, como a perspectiva de gênero, na abordagem dos agravos e sofrimentos experimentados pelo(a)s usuário(a)s. Nesse sentido, as considerações feitas podem servir de referencial para uma aproximação também de gênero do adoecimento, sem dizer da vantagem que representam para a formulação e negociação das ações de cuidado relativas à situação de violência em que muitos dos usuários dos serviços de saúde se encontram. 


\section{Colaboradores}

MT Couto, LB Schraiber, AFPL d'Oliveira e LB Kiss participaram igualmente de todas as etapas da elaboração do artigo.

\section{Referências}

1. Schraiber LB, d' Oliveira AF. Violência contra mulheres: interfaces com a saúde. Interface - Comunicação, Saúde e Educação 1999; 3(5):41-54.

2. Heilborn ML, Sorj B. Estudos de gênero no Brasil. In: Miceli S, organizador. O que ler na ciência social brasileira 1970 1975: sociologia. São Paulo-Brasília: Editora Sumaré-Capes; 1999. p. 223-35

3. Couto MT, Schraiber LB. Homens, saúde e violência: novas questões de gênero no campo da Saúde Coletiva. In: Minayo MCS, Coimbra Jr CEA, organizadores. Críticas e atuantes: ciências sociais e humanas em saúde na América Latina. Rio de Janeiro: 2005. p. 687-706.

4. DaMatta R. A casa e a rua. Rio de Janeiro: Editora Guanabara; 1987.

5. Schraiber LB, d'Oliveira AF, Couto MT; Figueiredo WS. Violência dói e não é direito. A violência contra a mulher, a saúde e os direitos humanos. São Paulo: Unesp; 2005.

6. World Health Organization. Putting women's safety first: Ethical and safety recommendations for research on domestic violence against women. Geneva: Global Programme on Evidence for Health Policy. Publication n.WHO/EIP/GPE/99.2 1999.

7. Pope C, Mays N. Pesquisa qualitativa na atenção à saúde. Porto Alegre: Artmed; 2005.

8. Giffin K. Esfera de reprodução em uma visão masculina. Considerações sobre articulação da produção e reprodução de classe e de gênero. Phisis: Revista de Saúde Coletiva 1994 4(1): 146-55.

9. Leal OF, Boff AM. Insultos, queixas, sedução e sexualidade: fragmentos de identidade masculina em uma perspectiva relacional. In: Parker R, Barbosa R. Sexualidades brasileiras. Rio de Janeiro: Relume Dumará ABIA, IMS/Uerj; 1996. p. $119-35$
10. Almeida MV. Gênero, masculinidade e poder: revendo um caso do sul de Portugal. Anuário Antropológico/95 1996. Rio de Janeiro: Tempo Brasileiro; 61-89.

11. Da Matta R. "Tem pente ai?" Reflexões sobre a identidade masculina. In: Caldas D, organizador. Homens: comportamento, sexualidade e mudança; São Paulo: Senac; 1997. p. 45-62.

12. Nascimento PFG. "Ser homem ou ser nada": diversidade de experiências e estratégias de atualização do modelo hegemônico da masculinidade em Camaragibe/PE [dissertação]. Recife: Universidade Federal de Pernambuco; 1999.

13. Pitt-Rivers J. Honra e posição social. In: Peristiany JG, organizador. Honra e vergonha: valores da sociedade mediterrâneas Lisboa: Fundação Calouste Gulbenkian; 1971. p. 11-60w

14. d' Oliveira AFPL. Violência de gênero, necessidades de saúde e uso de serviços em atenção primária [tese]. São Paulo: Faculdade de Medicina Preventiva da Universidade de São Paulo; 2000.

15. Duarte LFD. Pouca vergonha, muita vergonha: sexo e moralidade entre as classes trabalhadoras urbanas. In: Lopes JSL, organizador. Cultura e identidade operária. Rio de Janeiro: UFRJ/Marco Zero; 1987. p. 203-26.

16. Suárez M, Machado L, Bandeira L. Violência, sexualidade e saúde reprodutiva. In: Galvão L, Díaz J. Saúde sexual e reprodutiva no Brasil. São Paulo: Hucitec; 1999. p. 277-309.

Artigo apresentado em 28/03/2006

Artigo aprovado em 7/07/2006

Versão final apresentada em 16/08/2006 